outcome is difficult to judge, but certainly many of the final necropsy diagnoses would have been amenable to active medical treatment. Interestingly, the incidence of clinical misdiagnosis was similar in both teaching and non-teaching hospitals. Three additional cases in my records also illustrate that jaundice in a patient with a previously established diagnosis of malignancy should not be attributed to carcinomatosis in the absence of histological evidence of spread, the final necropsy diagnoses in these cases being chest infection, cirrhosis, and amyloidosis. It is particularly important that a false positive isotope liver scan was again the main cause of clinical difficulty.

During the same period my necropsies have shown only one histopathological misdiagnosis of malignancy, although four cases of cytopathological error are recorded, an error surprisingly not experienced by Dr Rees and colleagues in their 1635 admissions.

Dr Rees and coworkers support my long held view that a clinical diagnosis of terminal cancer must always be supported by a definitive histopathological diagnosis. In addition, it would seem desirable for cytopathological diagnoses to receive tissue confirmation whenever possible.

For reasons that remain obscure, the unqualified and grossly inadequate term "carcinomatosis" remains acceptable to both registrars and referees on death and cremation certificates. Fortunately, however, some coroners place histologically unproved carcinomatosis in the "cause of death which appears to be unknown" category and request the performance of a necropsy in such cases. My statistics illustrate that such a policy is well founded and should receive wider, if not national, acceptance by all those concerned with certification of death.

David SLATER

Rotherham District Hospital,

Rotherham S60 2UD

\section{Pinch skin grafting or porcine dermis in venous ulcers}

SIR,-We would like to address the first two paragraphs of Dr L O Simpson's letter (4 July, p 53).

Our preliminary findings after measuring transcutaneous oxygen tension at $43^{\circ} \mathrm{C}$ (in the inner aspect of the lower third of the leg) in patients with venous, mixed arteriovenous, and arterial ulcers enabled us to discriminate between patients and controls as well as between ulcers of venous and other aetiologies.'

In the same preliminary communication we also reported our inability to agree with the findings of Dodd et al, who measured oxygen tension at $37^{\circ} \mathrm{C}$ on the dorsum of the foot and found very low absolute values. ${ }^{2}$ The point that we would like to emphasise, as Dr Simpson draws support from Dodd $e t a l$, is that transcutaneous oxygen tension measured at $37^{\circ} \mathrm{C}$ yields very low absolute values (2-10 $\mathrm{mm} \mathrm{Hg}$ ), and changes within such small absolute values must be interpreted cautiously.

Percentage change in blood flow on dorsum. Information in parentheses indicates change on dependence ${ }^{\star}$

\begin{tabular}{|c|c|c|}
\hline & Mean (SD) & Range \\
\hline \multicolumn{3}{|l|}{$\begin{array}{l}\text { Patients with venous } \\
\text { disease and ulcers } \\
(n=19)\end{array}$} \\
\hline $\begin{array}{l}\text { Controls }(n=9) \\
\text { Patients with venous }\end{array}$ & $55 \cdot 2(27 \cdot 2)$ (decrease) & $26 \cdot 6-100$ \\
\hline $\begin{array}{l}\text { dusease and uicers } \\
(\mathrm{n}=3)\end{array}$ & $386 \cdot 2$ (increase) & $87 \cdot 5-700$ \\
\hline
\end{tabular}

$\star \%$ Change $=($ supine - dependent $) /$ supine.
We have obtained many results using the protocol described in our preliminary communication, and at present our findings are consistent with the concept of a barrier to oxygen transport in the legs of patients with venous disease. Clyne $e t$ al, who reported findings of oxygen tension similar to ours, support the concept of the fibrin barrier proposed by Professor Browse. ${ }^{3}$ Other workers, notably Bollinger $e t a l^{4}$ and Fagrell, ${ }^{5}$ have used sodium fluorescene to image the veins and have reported observing "haloes" of micro-oedema around capillaries in the skin of patients with chronic venous incompetence. These workers suggest that such "haloes" may act as barriers to the transport of oxygen to tissues.

Dr Simpson has also extrapolated from Dodd et al's findings to say that "it is unlikely that vascular changes occurred when the body changed from the horizontal to the vertical plane." We have investigated the change in blood flow in the dorsum of the foot after a passive lowering of the foot from the supine position through $50 \mathrm{~cm}$. The table shows the changes in cutaneous blood flow measured on the dorsum with a laser Doppler flowmeter (Periflux PF1C, Perimed, Sweden). The decrease in blood flow agrees with the findings of Hassan and Tooke. ${ }^{6}$ The increase measured in the three patients was absent when experiments were repeated with patients wearing graduated compression bandaging.

Wessex Regional Medical Physics Department,

R MANI

Southampton General Hospital,

Southampton General Hosp
Southampton $\mathrm{SO} 9 \mathrm{XY}$

1 Mani R, Gorman FW, White JE. Transcutaneous measurements of oxygen tension at edges of leg ulcers: preliminary communication. I $R$ Soc Med 1986;79:650-4.

2 Dodd HJ, Gaylarde PM, Sarkany I. Skin oxygen tension in venous insufficiency of the lower leg. $\mathcal{F} R$ Soc Med 1985;78: 373-6.

3 Clyne CAC, Ramsden WH, Chant ADB, Webster JH. Oxygen tension of the skin of the gaiter area of limbs with venous disease. Br F Surg 1985;72:644-7.

4 Bollinger $A$, Junger $M$, Jager $K$. Fluorescence videomicroscopy techniques for the evaluation of human skin microcirculation. techniques for the evaluation of hur.

5 Fagrell B. Local microcirculation in chronic venous incom petence and leg ulcers. Vascular Surgery 1979;13:4.

6 Hassan AAK, Tooke JE. Effect of local nervous blockade on postural vasoconstriction in man. Proceedings of the Physiolo gical Society 1986;381:63.

\section{Cervical carcinoma: prognosis in younger} patients

SIR,-The review by $\mathrm{Dr} J \mathrm{M}$ Russell and colleagues (1 August, p 300) of 2870 patients with cervical carcinoma showed results that were compatible with the Office of Population Censuses and Surveys' returns for similar years. ${ }^{1}$ The age related incidence of cervical cancer is, however, now different. Individual gynaecologists have for some years been aware of a dramatic increase in the disease in very young women. This is now apparent in the Office of Population Censuses and Surveys returns and since 1985 figures for women aged 15 24 have been cited. Compared with 1976-80 the number of reported cases of carcinoma of the cervix in women aged 25-34 rose from 348 to 492 , an increase of $41 \%$. This increase has continued after the period of analysis covered by the paper by Dr Russell and coworkers. ${ }^{2}$

In young women the degree of tumour differentiation and the rate of tumour progression are likely to dictate outcome. Hall and Monaghan reported on a small series of women under 35 years with cervical carcinoma; all five with microinvasion were alive, but of the remaining 37 patients with squamous carcinoma, 34 had poorly differentiated or anaplastic tumours and 17 were dead. ${ }^{3}$ Although it does not give survivals at five years, this report is alarming. The study by Dr Russell and colleagues, valuable as it is, is a retrospective analysis of a retrospective situation. A similar study in 1997 may well tell a different story.

ANTHONY D G ROBERTS

Department of Obstetrics and Gynaecology,

University of Leicester,

Leicester Royal Infirmary,

Leicester LE2 7LX

Office of Population Censuses and Surveys. OPCS monitor London: Office of Population Censuses and Surveys, 198t (MB1 84/1.)

2 Office of Population Censuses and Surveys. OPCS monitor. London: Office of Population Censuses and Surveys. 1986 (MB1 86/1.)

3 Hall SW, Monaghan JH. Invasive carcinoma of the cervix in younger women. Lancet 1983;ii:731.

SIR,-Dr M Ashby (27 June, $p$ 1688) and Dr J M Russell and colleagues (1 August, p 300) suggest that the prognosis for young women with cervical carcinoma is as good as, if not better than, that in older women, despite previous reports to the contrary. ${ }^{1}$

I reviewed the records of all patients with invasive squamous cancer of the cervix presenting to the radiation oncology unit at the Western General Hospital in Edinburgh in the years 1974 and 1983. Though the overall numbers had altered little (75 patients in 1974, 83 in 1983), the proportion of women under 35 had increased from $4 \%$ in 1974 to $18 \%$ in 1983 . Only three cases $(4 \%)$ in 1974 and five $(6 \%)$ in 1983 were detected by routine cervical cytology; the rest of the women had symptoms at the time of diagnosis.

Of the young women who presented in 1983 most presented with International Federation of Gynaecology and Obstetrics stage Ib $(67 \%)$ or II $(27 \%)$ disease, and $54 \%$ of all patients had stage $\mathrm{Ib}$ and II disease. Of the women under 35 , half were shown to have lymph node disease by lymphangiography or node biopsy. Treatment was by external beam radiotherapy and intracavitary caesium or by radical hysterectomy and external beam radiotherapy (eight patients).

After one year $27 \%$ of those under 35 had died of their disease (all had had lymph node disease). By contrast, only $11 \%$ of women over 35 with stage Ib and II disease had died at one year, and three of these four women were in the 36 to 40 age group. Though the numbers are small and figures for five year survival cannot be given, these findings do not support the suggestion that stage for stage survival in women under 35 is as good as that in older women.

SHEENA Pinion

Glasgow

I Stanhope CR, Smith JP, Wharton JT, Rutledge FN, Fletcher GH, Gallagher HS. Carcinoma of the cervix: the effect of age on survival. Gynecol Oncol 1980;10:188-93.

\section{Ruptured abdominal aortic aneurysm} presenting as ureteric colic

SIR,-We believe that the presentation of a ruptured abdominal aneurysm as ureteric colic, as discussed by $\mathrm{MrC} \mathrm{G}$ Moran and colleagues (16 May, p 1279) and Dr J B Roussak and MrE R C T Owen (25 July, p 267), is so common that all the staff in the urology department are routinely told consciously to exclude a leaking aneurysm in all cases of ureteric colic in patients over 50 years old To our knowledge there have been four such cases in the past 12 months in Bristol.

We would also like to point out the hazards of relying on ultrasound for the diagnosis of ruptured abdominal aortic aneurysm. Recently, a 60 year old man was referred to the department of urology from the accident and emergency department 